\title{
Do Rats Show a Mozart Effect?
}

\author{
KENNETH M. STEELE \\ Appalachian State University
}

The "Mozart effect" is an increase in spatial reasoning scores after listening to a Mozart piano sonata. Both the production and interpretation of the effect are controversial. Many studies have failed to replicate the original effect. Other studies have explained a Mozart effect as being caused by changes in arousal or differences in preferences of the listener. F. H. Rauscher, K. D. Robinson, and J. J. Jens (1998) reported that rats learned to complete a T-maze more quickly if they had been exposed in utero and reared hearing a Mozart piano sonata. They concluded that the result indicated a direct effect of the music on brain development and contradicted competing accounts of arousal or preference. This article is an analysis of the experiment by Rauscher et al. The in utero exposure would have been ineffective because rats are born deaf. A comparison of human and rat audiograms, in the context of the frequencies produced by a piano, suggests that adult rats are deaf to most notes in the sonata. The successful performance of the Mozart group may be explained by the incomplete use of random assignment of subjects to groups and by experimenter effects in the construction of groups. The results of Rauscher et al. (1998) do not provide strong support for the existence of the Mozart effect.

Received June 3, 2002, accepted July 23, 2003

$\mathrm{T}^{\mathrm{HE}}$ original "Mozart effect" is an increase in spatial reasoning scores after listening to the first section of a Mozart piano sonata, the Sonata for Two Pianos in D Major, K. 448 (Rauscher, Shaw, \& Ky, 1993, 1995). Rauscher et al. $(1993,1995)$ interpreted their results and concluded that hearing the music caused the improvement through direct neural priming of spatial reasoning areas in the brain. This interpretation was used as the basis for their strong advocacy of exposure to music in schools to improve mathematics scores (Rauscher, 1997, 1999a; Shaw, 2000).

Shaw (2001) has enlarged the domain of the Mozart effect to include reports that patients with Alzheimer's disease/dementia show improved

Address correspondence to K. M. Steele, Department of Psychology, Appalachian State University, Boone, NC 28608. (e-mail: steelekm@appstate.edu)

ISSN: 0730-7829. Send requests for permission to reprint to Rights and Permissions, University of California Press, 2000 Center St., Ste. 303, Berkeley, CA 94704-1223. 
performance on a visual-spatial task after hearing the Mozart piano sonata (Johnson, Cotman, Tasaki, \& Shaw, 1998; Johnson, Shaw, Vuong, Vuong, \& Cotman, 2002) and that exposure to this piano sonata reduced seizure activity in epileptic patients, even when the person was in a coma and therefore unconscious (Hughes, Daaboul, Fino, \& Shaw, 1998). Shaw includes in this "Mozart effect generalized" a study by Rauscher, Robinson, and Jens (1998) which reports that long-term exposure of rats to this Mozart piano sonata produced enhanced maze-learning. An analysis of the Rauscher et al. (1998) experiment is the subject of this article.

The existence of the original Mozart effect is a matter of great controversy. More laboratories have been unable to produce a Mozart effect (Bridgett \& Cuevas, 2000; Carstens, Huskins, \& Hounshell, 1995; Kenealy \& Monsef, 1994; McCutcheon, 2000; McKelvie \& Low, 2002; Newman, Rosenbach, Burns, Latimer, Matocha, \& Vogt, 1995; Ong, Lu, \& Smith, 2000; Steele, Bass, \& Crook, 1999; Steele, Dalla Bella, et al., 1999; Stephenson, 2002; Stough, Kerkin, Bates, \& Mangan, 1994; Weeks, 1996) than have been able to produce the effect (Nantais \& Schellenberg, 1999; Rideout \& Laubach, 1996). Even positive results have been interpreted as being explained by arousal or preference differences instead of musical priming of spatial reasoning areas of the brain (Chabris, 1999; Husain, Thompson, \& Schellenberg, 2002; Nantais \& Schellenberg, 1999; Steele, 2000; Steele, Ball, \& Runk, 1997; Thompson, Schellenberg, \& Husain, 2001).

Chabris (1999) conducted a meta-analysis of published studies and concluded that music enhanced spatial reasoning a trivial amount $(d=0.14$ standard deviation [SD] units, the equivalent of 2.1 IQ points) when the control condition was silence. The effect size was increased $(d=0.56 \mathrm{SD}$ units) when the control condition was auditory relaxation instructions. Because relaxation instructions are designed to reduce arousal, Chabris concluded that arousal differences explain cases in which a Mozart effect is found. Hetland (2000) published a meta-analysis that came to a different conclusion. Hetland concluded that the effect size was much larger $(d=$ 0.50 SD units) for spatial task performance. What accounts for the discrepancy between the two reports? One important difference was that Hetland chose to include unpublished results. This choice produced the inclusion of several studies from a specific laboratory (Rauscher, Bowers, \& Kohlbeck, 1999; Rauscher \& Hayes, 1999; Rauscher \& Ribar, 1999). However, Hetland's meta-analysis found a "lab effect" also. Results from Rauscher's lab showed significantly stronger Mozart-effect results relative to all other labs (Hetland, 2000, p. 134). Mean effect size from Rauscher's lab was more than twice as large as results from other labs. Hetland suggested that this difference may be due to unidentified procedural differences. This produces a problem for evaluation of Hetland's overall conclusion about the Mozart effect because it is difficult to evaluate procedural differences when the studies of interest are unpublished. 
Rauscher and Shaw (1998) suggested that failures were due to inappropriate procedures or inappropriate spatial reasoning measures. However Steele, Bass, and Crook (1999) replicated the procedure of Rauscher et al. (1995) and were unable to produce a Mozart effect. Steele, Dalla Bella, Peretz, et al. (1999) were unable to produce a Mozart effect in three experiments that used the general procedures of both experiments by Rauscher et al. Rauscher (1999b) suggested these negative results were caused by procedural artifacts. Rauscher's main criticism was Steele et al.'s use of random assignment of subjects to experimental conditions. Rauscher et al. (1995) used results from a pretest to construct "equivalent groups" before the experimental session.

Rauscher (1999b) and Shaw (2000) have cited the experiment by Rauscher et al. (1998) as additional proof of the existence of the effect. Rauscher et al. (1998) reported the production of a Mozart effect in rats. The result was interpreted to indicate that the Mozart effect is a neurophysiological effect, not a cultural or arousal-preference effect, which "provides a window into higher brain function" (Shaw, 2000). This article analyses that experiment to determine whether a Mozart effect was produced in rats.

\section{The Rauscher et al. (1998) Experiment}

Rauscher et al. (1998) bred rats in the presence of a repeating 8 min 24 s tape loop of either the first portion of the Mozart piano sonata (K. 448), an equivalent duration from Philip Glass's Music With Changing Parts, or white noise. The pregnant rats received continued exposure to their original sound condition (Mozart, Glass, or White Noise) for $12 \mathrm{~h}$ per day at an intensity of 65 to $70 \mathrm{~dB}$ throughout the gestation period. After birth, rat pups were exposed additionally to that sound condition for another 60 days, $12 \mathrm{~h}$ per day. After weaning, all animals were handled for 1 min daily to accustom them to human contact. Beginning on the 61st day, 90 rats (30 per sound-rearing condition, equal numbers of males and females) were trained on a six-unit T-maze. Each sound-condition group was further subdivided into three groups of 10 , and each subgroup was trained in the maze in the presence of either the Mozart sonata, the Glass music, or white noise. Sound levels in the maze registered 65 to $70 \mathrm{~dB}$. Testing was performed "blind" over the course of 5 days, three trials per day, with 10-min rest periods between trials. (The "blinding" procedure was not described.) Trials were videotaped. Dependent measures were working time in the maze and errors (blind-alley entrances).

Rauscher et al. (1998) reported that the Mozart-reared group performed significantly better at learning the maze. The Mozart group produced significantly fewer blind-alley entrances than the white-noise group on the 
first day of training. The Mozart-reared rats learned over days to reach the reward more quickly than the Glass or White Noise groups. There was no effect of the specific music played during training inside the maze, and there was no significant interaction between music-rearing condition and music-in-the-maze condition. A Mozart-reared rat reared was not hampered by having Glass played in the maze, and a Glass-reared rat was not helped by having Mozart played in the maze.

Rauscher et al. (1998) conducted a second experiment to test whether the rearing-condition difference could be due to a decrease in performance in the Glass and White Noise groups. Two groups $(N=12$ and $N=8)$ were exposed to silence in utero and 60 days postpartum and then tested in the maze during exposure to either silence or white noise. A third group $(N=$ 8 ) was exposed to white noise originally and then tested in silence. Rauscher et al. found no significant effect of rearing condition or significant interaction between rearing condition and sound condition in the maze. Learning performance was unaffected by switches to a new sound stimulus in the maze.

Rauscher (1999b) and Shaw $(2000,2001)$ did not explain why rats would be expected to show a Mozart effect and cited no work demonstrating that listening to classical music would improve learning in rats. A review of the literature indicated that only two studies had examined the specific effect of classical music on rats before Rauscher et al. (1998). The results of both studies raised questions about what rats heard of the music.

\section{What Is the Effect of Classical Music on Rats?}

Cross, Halcomb, and Matter (1967) investigated imprinting to sound by having groups of rats reared listening to music either by Mozart or by Schoenberg and asked whether rearing condition would predict sound preference in a choice task. The Mozart group did show a preference for Mozart over Schoenberg but the Schoenberg group did not prefer Schoenberg. Cross et al. explained the lack of preference of the Schoenberg group as possibly due to differences in vividness, intensity, or attention-getting characteristics between the two sets of music. In other words, Cross et al. expressed concern that the Schoenberg rats had not heard their music well enough to produce an imprinting effect.

Bates and Horvath (1971) investigated whether exposure to classical music would improve discrimination learning in rats. Rats were trained to solve a visual discrimination task in the presence of either a Mozart symphony, a monotonic amelodic version of that Mozart symphony (which preserved only the rhythm component), a Schoenberg chamber symphony, a monotonic amelodic version of the Schoenberg selection, white noise, or quiet. Bates and Horvath found that rats trained in the presence of Mozart 
produced more correct responses than rats exposed to Schoenberg but there were no differences in learning rate between rats that heard the original music and rats that heard the altered music, for both the Mozart and Schoenberg group. In other words, greatly altering the music did not affect the rats' rate of learning. Finally, the best discrimination performance was produced by the rats in the quiet condition. The lack of effect of altering the music suggests that rats may not hear all aspects of the music.

\section{What Is the Effect on a Rat of in Utero Exposure to Music?}

Rauscher et al. (1998) argued for the need to establish an animal model to investigate the physiology of the Mozart effect but did not explain why rats were chosen as the appropriate model. The use of animal models has a long and honorable history. However, one must always be concerned that one has made the appropriate translation from one domain to another. Rauscher et al. (1998) treated rats as if they were humans by exposing the rats to the music in utero. The human infant hears at birth, and there is evidence that the fetus responds to vibration by 26 weeks (Gagnon, Hunse, Carmichael, Fellows, \& Patrick, 1987). Some mammals hear at birth, including goat and guinea-pig, but many mammals do not, including ferrets, gerbils, and rats (Sohmer \& Freeman, 1995). Rats are deaf to air-borne sounds until about 11 days after birth. Geal-Dor, Freeman, Li, and Sohmer (1993) exposed young rats from birth through 10 days old to $135 \mathrm{~dB}$ SPL click stimuli without provoking a response in auditory brainstem neurons. Deafness is due, in part, to lack of conduction of sound because the bones of the middle ear have not ossified. In addition, the newborn rat shows sensorineural deafness. The earliest auditory brainstem response to direct 80 -dB vibration of the skull does not appear until a week after birth (GealDor et al., 1993) and a cochlear microphonic response does not appear for another 2 days (Uziel, Romand, \& Marot, 1981).

\section{What Sound Frequencies Do Humans and Rats Hear?}

The approach of Rauscher et al. was to expose rats to music, using the same music selections at the same sound intensities as were used in their human-subject experiments. This procedure was based on the assumption that musical stimuli appropriate for human hearing would suffice for rats. The available evidence from comparative psychophysics indicates that the assumption was wrong.

Figure 1 shows a typical human audiogram (Jackson, Heffner, \& Heffner, 1999). The figure shows how intense a sound must be to be above absolute

threshold for different frequencies. A value of $0 \mathrm{~dB}$ SPL is the conventional 


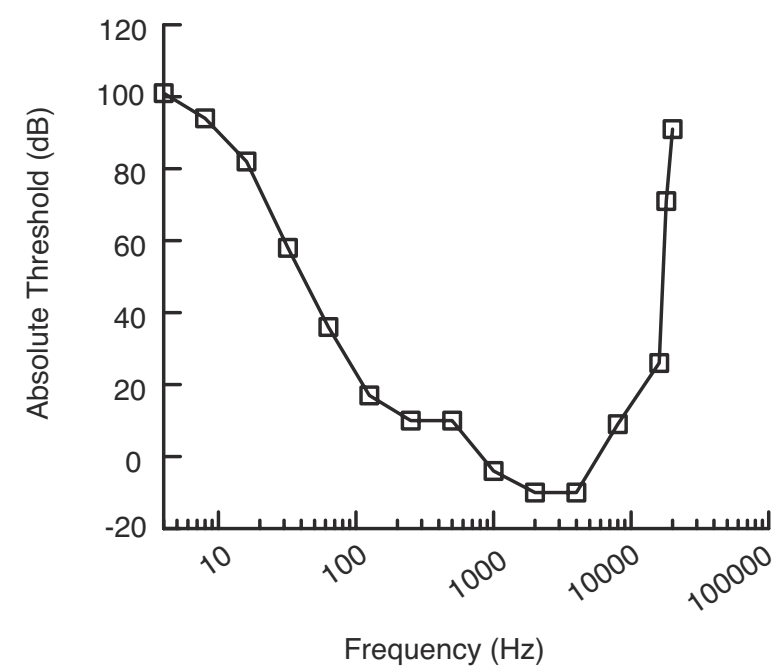

Fig. 1. Human audiogram illustrating the relationship of absolute threshold to stimulus frequency. Stimulus intensity was measured in decibels (dB SPL), and frequency was measured in Hertz. Note that frequency is reported on a log scale. Greater sensitivity is indicated by lower threshold values. The results are from Jackson et al. (1999).

absolute threshold for human hearing. Each increment of $20 \mathrm{~dB}$ indicates that the physical intensity of the stimulus has been increased by a factor of 10 (Matlin \& Foley, 1997, p. 281). The change from 0 to $100 \mathrm{~dB}$ represents a change by a factor of 100,000 in the intensity of the stimulus. Although it is true that the typical human hearing range is from $20 \mathrm{~Hz}$ to $20,000 \mathrm{~Hz}$, it is clear that we are not sensitive equally to sounds across that range. The figure illustrates that human hearing may be broken roughly into three bands: below $100 \mathrm{~Hz}, 100$ to $8000 \mathrm{~Hz}$, and above $8000 \mathrm{~Hz}$. Human hearing is sensitized to detect and discriminate among sounds in the middle band, the location of speech frequencies. The lower and higher frequency bands are used primarily for sound localization (Coren, Ward, \& Enns, 1999; Stevens \& Newman, 1934, 1936).

Table 1 shows the fundamental frequencies associated with each note on the piano keyboard (Reblitz, 1976). The table shows notes organized in columns by octaves and in rows by note names. " $\mathrm{C}_{4}$ " designates the " $\mathrm{C}$ " note in the fourth octave and is referred to as "middle C." The range of frequencies across the entire keyboard is from $27.5 \mathrm{~Hz}$ to $4186 \mathrm{~Hz}$, and the range for the two middle octaves is from $220 \mathrm{~Hz}\left(\mathrm{~A}_{4}\right)$ to $831 \mathrm{~Hz}\left(\mathrm{G}_{5}\right)$. Both sets of ranges indicate that piano note frequencies are located where our hearing is most sensitive. This is not surprising because humans developed the piano to affect human ears.

Figure 2 shows the addition of a typical audiogram for Rattus into Figure 1 (Heffner, Heffner, Contos, \& Ott, 1994; also see additional audio- 
TABLE 1

Theoretical Fundamental Frequencies for the 88 Piano Notes

\begin{tabular}{lcccccccc}
\hline & \multicolumn{7}{c}{ Octaves } \\
\cline { 2 - 9 } Note & 1 & 2 & 3 & 4 & 5 & 6 & 7 & 8 \\
\hline $\mathrm{G \#}$ & 51.913 & 103.826 & 207.652 & 415.305 & 830.609 & 1661.219 & 3322.437 & \\
$\mathrm{G}$ & 48.999 & 97.999 & 195.998 & 391.995 & 783.991 & 1567.982 & 3135.437 & \\
$\mathrm{~F} \#$ & 46.249 & 92.499 & 184.997 & 369.994 & 739.989 & 1479.978 & 2959.955 & \\
$\mathrm{~F}$ & 43.654 & 87.307 & 174.617 & 349.228 & 698.456 & 1396.913 & 2793.826 & \\
$\mathrm{E}$ & 41.203 & 82.407 & 164.814 & 329.629 & 659.255 & 1318.520 & 2637.020 & \\
$\mathrm{D} \#$ & 38.891 & 77.782 & 155.563 & 311.127 & 622.254 & 1244.598 & 2489.016 & \\
$\mathrm{D}$ & 36.708 & 73.416 & 146.832 & 293.665 & 587.330 & 1174.659 & 2439.318 & \\
$\mathrm{C} \#$ & 34.648 & 69.296 & 138.591 & 277.183 & 554.365 & 1108.731 & 2217.461 & \\
$\mathrm{C}$ & 32.703 & 65.406 & 130.813 & 261.626 & 523.251 & 1046.502 & 2093.004 & 4186.009 \\
$\mathrm{~B}$ & 30.868 & 61.735 & 123.471 & 246.942 & 493.883 & 987.767 & 1975.533 & 3951.066 \\
$\mathrm{~A} \#$ & 29.135 & 58.270 & 116.541 & 233.082 & 466.164 & 932.328 & 1864.655 & 3729.310 \\
$\mathrm{~A}$ & 27.500 & 55.000 & 110.000 & 220.000 & 440.000 & 880.000 & 1760.000 & 3520.000 \\
\hline
\end{tabular}

grams in Fay, 1988). The figure indicates that the audiogram for the rat is shifted toward much higher frequencies, with lowest thresholds at 8,000 $\mathrm{Hz}$ and $32,000 \mathrm{~Hz}$. One reason for the shift in frequency sensitivity is sound localization (Heffner \& Heffner, 1998). The pinna (outer ear) and the head alter the characteristics of the sound signal to produce sound-level differences between the ears and these intensity differences are then used in sound localization. There is an inverse relationship between the size of the head

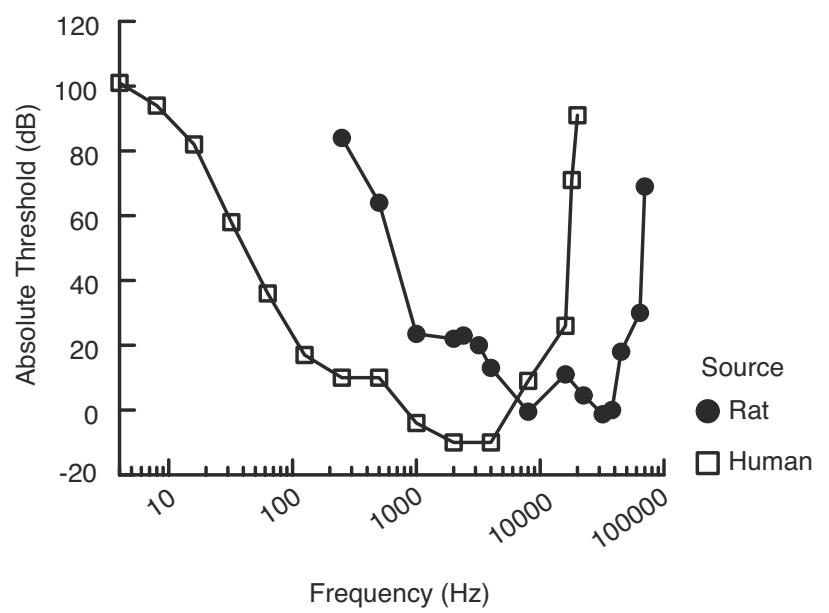

Fig. 2. Relationship between human audiogram and rat audiogram. Stimulus intensity was measured in decibels (dB SPL), and frequency was measured in Hertz and is reported on a $\log$ scale. Greater sensitivity is indicated by lower threshold values. The human results (unfilled squares) are from Jackson et al. (1999) and the rat results (filled circles) are from Heffner et al. (1994). 
cum pinna and the sound frequencies most affected. Smaller heads work best with the attenuation of higher frequencies. A shift to higher-frequency sensitivity permits rats to use differences between the ears to localize sounds successfully.

\section{What Notes Would Be Heard in the Mozart Piano Sonata?}

Figure 3 shows the addition of dashed lines to indicate the location of 65 and $70 \mathrm{~dB}$, the sound-intensity range used by Rauscher et al. (1998). Frequency points above the lines indicate frequency values that would require a higher intensity than was presented in the Rauscher et al. experiment to be above absolute threshold. These frequencies would not be heard at the sound intensity used in the Rauscher et al. experiment. The dashed-lines intersect the rat audiogram at approximately $500 \mathrm{~Hz}$, and suggest that sounds below $500 \mathrm{~Hz}$ were below absolute threshold for the rats in this experiment. The values in Table 1 indicate that $500 \mathrm{~Hz}$ corresponds to a point between $\mathrm{B}_{5}$ and $\mathrm{C}_{5}$ on the keyboard. The location of this value suggests that piano notes from the lower four octaves would be below abso-

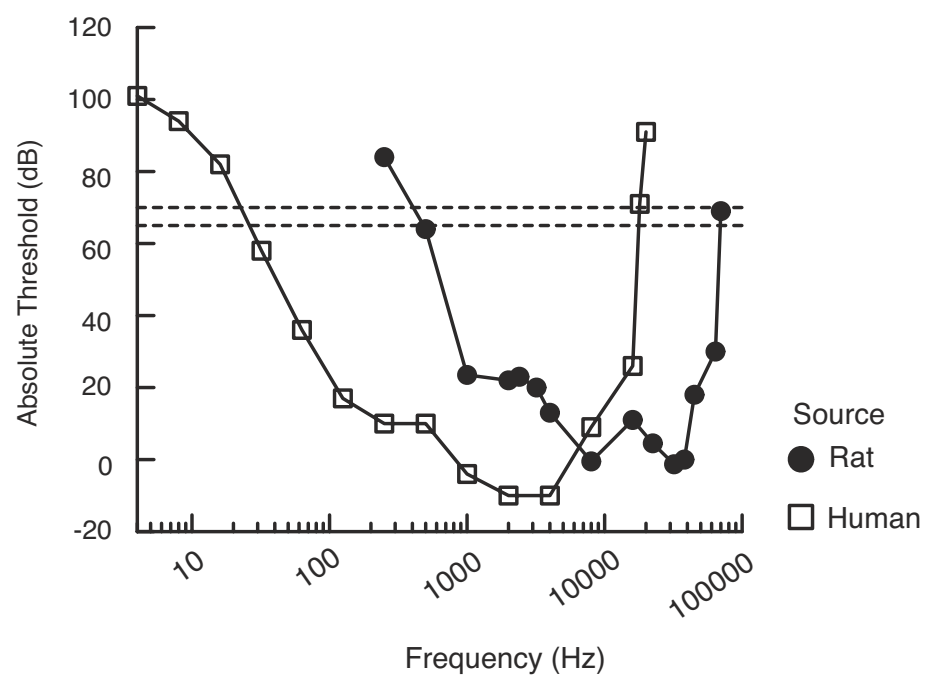

Fig. 3. Sound intensity cutoff lines applied to audiograms. The dashed lines indicate the range of amplitude of stimuli (from 65 to $70 \mathrm{~dB}$ ) used by Rauscher et al. (1998). In order to be above absolute threshold, frequency values located above the dashed line would require higher amplitudes than were provided in the experiment by Rauscher et al.. The dashed lines intersect the rat audiogram at approximately $500 \mathrm{~Hz}$, suggesting that frequencies below $500 \mathrm{~Hz}$ were inaudible. 
lute threshold for subjects in the Rauscher et al. (1998) experiment. This is a conservative estimate because the presence of other sounds, for example, the sound of a ventilation fan, would produce masking noises that would increase the absolute threshold of a note further.

Hypothesizing that only $\mathrm{C}_{5}$ and notes of higher frequency were above threshold would suggest that rats could hear only $37 / 88(42 \%)$ of the available piano notes. Therefore it is important to know which notes occurred in the Mozart piano sonata because rats would not have heard the lowerfrequency notes. A count of the amount of each note was obtained from a standard musical score (Hughes, 1926) for the first movement of the K. 448 sonata. Figure 4 shows the percentage of notes in the score, collapsed into octaves. The point for Octave 1 indicates the proportion of notes from that octave, and was computed from the sum of all occurrences of notes from $A_{1}$ to $G_{1}^{\#}$ divided by the total number of notes. Other octave percentages were calculated in a similar fashion. A line was established at $\mathrm{C}_{5}$, as notes above $\mathrm{C}_{5}$ were hypothesized to be above threshold and notes below $\mathrm{C}_{5}$ were below threshold. Based on this assumption, the rats in Rauscher et al. (1998) would not have heard 1913 (69\%) of the 2790 notes in the first movement.

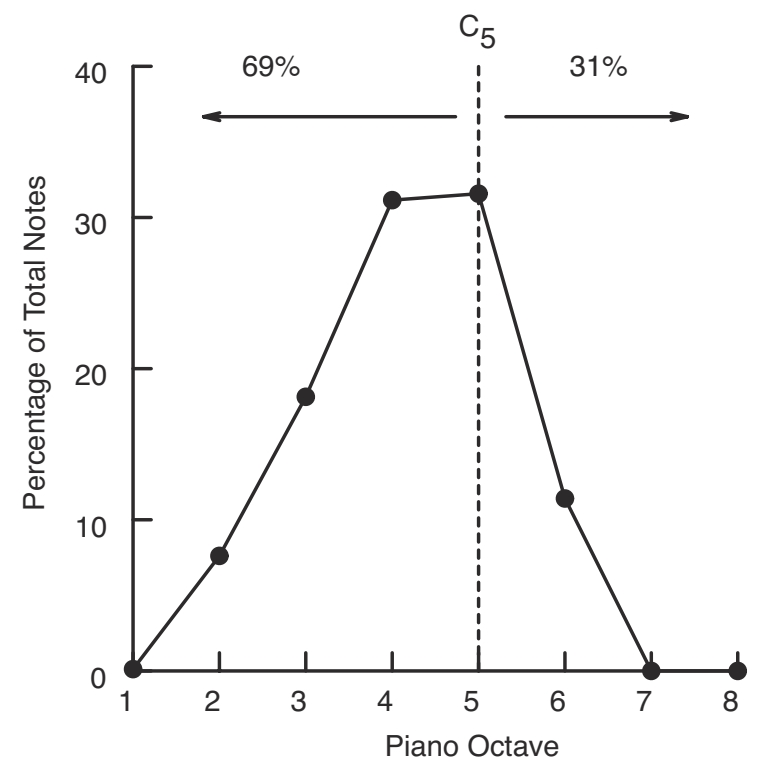

Fig. 4. Distribution of notes in the first section of Mozart's piano sonata K. 448. Each point shows the sum of notes in an octave divided by the total number of notes in the first section of K. 448. The note $\mathrm{C}_{5}$ ( $\mathrm{C}$ in the fifth octave) has a frequency of $523 \mathrm{~Hz}$ and marks the likely border between inaudible notes $(69 \%)$ and audible notes $(31 \%)$. 


\section{Discussion}

Did the Rauscher et al. rats show a Mozart effect? The evidence is against this conclusion. Exposure to the music in utero would have been ineffective because rats are deaf as newborns. What did adolescent rats hear when the Mozart piano sonata was played? A comparison of human and rat audiograms indicated clear differences between the two species. The range of hearing for rats is shifted to higher frequencies, relative to humans. In contrast, the frequency values of piano notes are located where human hearing is sensitive. The present analysis suggests that rats were deaf to much of the hypothesized enrichment effects of the music because more than half of the notes in the sonata were below absolute threshold for the rats in Rauscher et al. (1998). This is a conservative estimate because the effects of additional noises, such as the masking effects of a ventilation fan, were not included in the estimate.

The conclusion that the rats in Rauscher et al. (1998) were deaf to much of the music permits one to explain one puzzling result from the study. Rauscher et al. found that there was no effect of the music that was played in the maze. This was an odd finding because standard animal learning work would have suggested that subjects should have been disrupted by a change in their usual sound environment (i.e., generalization decrement). The lack of disruption would be consistent with the suggestion that rats heard little of the music, and therefore were not affected by the change in music in the maze.

What explains the positive findings by Rauscher et al. (1998)? The groups may have been systematically different for reasons other than music exposure. Remember that the Mozart-reared rats showed significantly less errors on the first day of training. This difference suggests that the Mozartreared group was behaving differently from other groups at the start of maze training. An analysis of the Rauscher et al. procedure suggests two factors that could have produced groups with pre-existing differences. First, their design violated the principle of random assignment of rat pups to music-rearing condition. All offspring from a particular mother were assigned to the same music condition. If a rat was impregnated in the presence of the Mozart sonata, then all her offspring would be assigned to the Mozart condition. This procedure introduces the problem of a "litter effect," that is, the offspring of a mother tend to be more similar to one another than to rats in other litters because of characteristics they inherit from the mother and their similar prenatal and postnatal environments (Caldji, Diorio, \& Meaney, 2000; Catalani et al., 2002; Pryce \& Feldon, 2003). Assignment of all offspring to the same condition confounds litter differences with listening-group differences. The immediate difference in 
error rates between the Mozart-reared group and the white-noise group may reflect litter differences between the groups that affected learning rate.

One means by which a litter effect would be translated into a mazelearning effect would be through differences in emotionality between litters. Early stress results in changes in emotionality of offspring and affects learning rates in adult rats. Mild prenatal stress of the mother will result in offspring with reduced fear reactions and increased learning rates (Fujioka et al., 2001). Increased levels of prenatal stress may produce a reversed pattern (Lehman, Stohr, \& Feldon, 2000). The impact of a stress manipulation would depend upon the emotional reactivity of the individual. Importantly, individual differences in emotional reactivity among rat mothers are transmitted to their offspring (Caldji et al., 2000). The most common postnatal stress manipulations involve handling of the rat pups by experimenters and periods of separation of pups and mothers (Pryce \& Feldon, 2003). At least the first condition was present in the Rauscher et al. experiment. (A typical control condition, and the typical method to reduce a litter-effect problem, is to cross-foster, i.e., spread the members of any one litter evenly among all mothers. Rauscher et al., 1998, did not do this because they thought they were studying the effect of music on the developing fetal brain.)

A second problem comes from the experimenter's construction of the final groups. Subjects were culled from groups after group assignment was known. The final three groups contained the same number of subjects, evenly divided between males and females. Creation of each group required culling of some number of subjects by the experimenter. Experimenters would not be blind to group assignment of the offspring during culling because the mother's listening condition was established already. Therefore the experimenter may have introduced some selection artifact during the culling operation that affected the final nature of the groups.

One selection artifact that would be of concern is inadvertent attention to the distance between anus and genitalia, the anogenital distance (AGD). From birth, rats are classified reliably as male or female based on observation of the AGD (Gallavan, Holson, Stump, Knapp, \& Reynolds, 1999). AGD is a marker that indicates hormone exposure also, with increased AGD indicating increased androgen exposure. Even female fetuses will be "masculinized" by developing in close uterine position to male fetuses, the "intra-uterine position" effect, and this exposure would be reflected by an increased AGD (Meisel \& Ward, 1981; Richmond \& Sachs, 1984; see Drickamer, 1996, for a recent review). Exposure to prenatal androgens increases learning rate in spatial mazes in both male and female rats (Isgor \& Sengelaub, 1998). Hence, inadvertent attention to an increased AGD could lead to the selection of a group of males and females that would show better spatial learning. 
A combination of both litter effects and selective culling could produce groups that would be systematically different in a fashion that would affect the rate of learning by the group in the maze. For example, any one individual rat may be more fearful to being placed in the maze than another rat. The litter-effect problem is that this first individual rat may be in a music group that contains brothers and sisters who may have a similar level of emotional reactivity, whereas the other rat is in a different music group that is composed of brothers and sisters who share that other rat's level of emotional reactivity to the situation. The culling of the groups may have led to the elimination of pups who appeared "different" from their littermates, which would magnify these litter effects. Thus superficially trivial and innocent steps could produce groups that would learn to run mazes at different rates independent of the assigned listening condition.

The preceding paragraphs suggest plausible speculations of how systematic learning-rate differences among groups could have been produced inadvertently by the Rauscher et al. procedure. The most plausible sequence would depend on a careful analysis of concrete details of the procedure. This may prove difficult to do because many important details may have gone unrecorded, such as the number of brothers and sisters in a group, or objectively undefined, such as the rule used to choose the animals to be culled.

The historical record makes clear that seemingly trivial deviations from true random assignment can have a major effect on results. Brady, Porter, Conrad, and Mason (1958) reported that monkeys who were required to lever press to avoid shock developed stomach ulcers more quickly than did yoked control subjects that had no control over shock rate. Brady's (1958) vivid analogy that the responding monkeys were like busy "executives" suffering from the stress of decision making was a captivating image. However, the general finding to come from this type of experimental situation was the reverse result (Weiss, 1971). The subjects who had no control over the amount of shock or were unable to predict its occurrence were the ones who suffered the most ulcers. Weiss concluded that Brady's atypical result likely came from a failure to use random assignment of subjects to condition. Monkeys who learned the avoidance task most quickly in a pretest were assigned to the executive role and subsequent work demonstrated high-responding subjects were the ones most likely to develop ulcers.

Rauscher (1999b) and Shaw (2000) suggested that the demonstration of the Mozart effect in rats rules out a procedural or cultural explanation of their results with humans. The present analysis suggests there was no Mozart effect in the Rauscher et al. (1998) study because the rats were deaf to the majority of notes in the sonata played in their experiment. An alternative explanation of their results is available because the design of the experiment confounded familial differences with group assignment and subjects 
were culled after group assignment was known. Either design problem could explain the different performances by the groups in a maze task. There is still no scientific reason to base intellectual enhancement programs on the existence of the Mozart effect. ${ }^{1}$

\section{References}

Bates, F. C., \& Horvath, T. (1971). Discrimination learning with rhythmic and nonrhythmic background music. Perceptual and Motor Skills, 33, 1123-1126.

Brady, J. V. (1958). Ulcers in "executive” monkeys. Scientific American, 199, 95-100.

Brady, J. V., Porter, R. W., Conrad, D. G., \& Mason, J. W. (1958). Avoidance behavior and the development of gastroduodenal ulcers. Journal of the Experimental Analysis of Behavior, 1, 69-72.

Bridgett, D. J, \& Cuevas, J. (2000). Effects of listening to Mozart and Bach on the performance of a mathematical test. Perceptual and Motor Skills, 90, 1171-1175.

Caldji, C., Diorio, J., \& Meaney, M. J. (2000). Variations in maternal care in infancy regulate the development of stress reactivity. Biological Psychiatry, 48, 1164-1174.

Carstens, C. B., Huskins, E., \& Hounshell, G. W. (1995). Listening to Mozart may not enhance performance on the revised Minnesota paper form board test. Psychological Reports, 77, 111-114.

Catalani, A., Casolini, P., Cigliana, G., Scaccianoce, S., Consoli, C., Cinque, C., et al. (2002). Maternal corticosterone influences behavior, stress response, and corticosteroid receptors in the female rat. Pharmacology, Biochemistry, \& Behavior, 73, 105-114.

Chabris, C. F. (1999). Prelude or requiem for the Mozart effect? Nature, 400, 826-827.

Coren, S., Ward, L. M., \& Enns, J. T. (1999). Sensation and perception (5th ed.). Ft. Worth, TX: Harcourt Brace.

Cross, H. A., Halcomb, C. G., \& Matter, W. W. (1967). Imprinting or exposure learning in rats given early auditory stimulation. Psychonomic Science, 7, 233-234.

Drickamer, L. C. (1996). Intra-uterine position and anogenital distance in house mice: Consequences under field conditions. Animal Behavior, 51, 925-934.

Fay, R. R. (1988). Hearing in vertebrates: A psychophysics databook. Winnetka, IL: HillFay Associates.

Fujioka, T., Fujioka, A., Tan, N, Chowdhury, G. M. I., Mouri, H., Sakata, Y., et al. (2001). Mild prenatal stress enhances learning performance in the non-adopted rat offspring. Neuroscience, 103, 301-307.

Gagnon, R., Hunse, C., Carmichael, L., Fellows, F., \& Patrick, J. (1987). Human fetal responses to vibratory acoustic stimulation from twenty-six weeks to term. American Journal of Obstetrics and Gynecology, 157, 375-381.

Gallavan, R. H. Holson, J. F., Stump, D. G., Knapp, J. F., \& Reynolds, V. L. (1999). Interpreting the toxologic significance of alterations in anogenital distance: Potential for confounding effects of progeny body weights. Reproductive Toxicology, 13, 383-390.

Geal-Dor, M., Freeman, S., Li, G., \& Sohmer, H. (1993). Development of hearing in neonatal rats: Air and bone conducted ABR thresholds. Hearing Research, 69, 236-242.

Heffner, H. E., \& Heffner, R. S. (1998). Hearing. In G. Greenberg, \& M. M. Haraway (Eds.), Comparative psychology: A handbook (pp. 290-303). NY: Garland Press.

1. I thank Henry Heffner and Dick Fay for their prompt and gracious assistance in supplying data to construct the audiograms. I thank Walter Bramel for doing the note count of the Mozart sonata. Portions of the material in this manuscript were presented at a meeting of the Psychonomic Society, in a talk for the North Carolina Cognition Group, and in a talk at Duke University, Durham, NC, in honor of the contributions and career of J. E. R. Staddon. 
Heffner, H. E., Heffner, R. S., Contos, C., \& Ott, T. (1994). Audiogram of the hooded Norway rat. Hearing Research, 73, 244-247.

Hetland, L. (2000). Listening to music enhances spatial reasoning: Evidence for the "Mozart effect." Journal of Aesthetic Education, 34, 105-148.

Hughes, E. (1926). Wolfgang Amadeus Mozart: Sonata in D and fugue in C minor for two pianos, four-hands (Vol. 1504). NY: G. Schirmer.

Hughes, J. R., Daaboul, Y., Fino, J. J., \& Shaw, G. L. (1998). The "Mozart effect" on epileptiform activity. Clinical Electroencephalography, 29, 109-119.

Husain, G., Thompson, W. F., \& Schellenberg, E. G. (2002). Effects of musical tempo and mode on arousal, mood, and spatial abilities. Music Perception, 20, 151-171.

Isgor, C. \& Sengelaub, D. R. (1998). Prenatal gonadal steroids affect adult spatial behavior, CA1 and CA3 pyramidal cell morphology in rats. Hormones and Behavior, 34, 183198.

Jackson, L. L., Heffner, R. S., \& Heffner, H. E. (1999). Free-field audiogram of the Japanese macaque (Macca fuscata). Journal of the Acoustical Society of America, 106, 30173023.

Johnson, J. K., Cotman, C. W., Tasaki, C., \& Shaw, G. L. (1998). Enhancement of spatialtemporal reasoning after a Mozart listening condition in Alzheimer's disease: A case study. Neurological Research, 20, 666-672.

Johnson, J. K., Shaw, G. L., Vuong, M., Vuong, S., \& Cotman, C. W. (2002). Short-term improvement on a visual-spatial task after music listening in Alzheimer's disease: A group study. Activities, Adaptation, and Aging, 26, 37-50.

Kenealy, P., \& Monsef, A. (1994). Music and IQ tests. The Psychologist, 7, 346.

Lehman, J., Stohr, T. \& Feldon, J. (2000). Long-term effects of prenatal stress experience and postnatal maternal separation on emotionality and attentional processes. Behavioral and Brain Research, 107, 133-144.

Matlin, M. W., \& Foley, H. J. (1997). Sensation and perception (4th ed.). Needham Heights, MA: Allyn and Bacon.

McCutcheon, L. E. (2000). Another failure to generalize the Mozart effect. Psychological Reports, 87, 325-330.

McKelvie, P., \& Low, J. (2002). Listening to Mozart does not improve children's spatial ability: Final curtains for the Mozart effect. British Journal of Developmental Psychology, 20, 241-258.

Meisel, R., \& Ward, I. (1981). Fetal female rats are masculinized by male littermates located caudally in the uterus. Science, 213, 239-242.

Nantais, K. M., \& Schellenberg, E. G. (1999). The Mozart effect: An artifact of preference. Psychological Science, 10, 370-373.

Newman, J., Rosenbach, J. H., Burns, K. L., Latimer, B. C., Matocha, H. R., \& Vogt, E. E. (1995). An experimental test of "the Mozart effect": Does listening to his music improve spatial ability? Perceptual and Motor Skills, 81, 1379-1387.

Ong, N. T., Lu, M. C., \& Smith, W. R. (2000, June). Effect of Mozart music on spatial reasoning: Another failure to replicate. Poster presentation at the 12 th annual meeting of the American Psychological Society, Miami Beach, FL.

Pryce, C. R., \& Feldon, J. (2003). Long-term neurobehavioral impact of postnatal environment in rats: Manipulations, effects and mediating mechanisms. Neuroscience and Biobehavioral Reviews, 27, 57-71.

Rauscher, F. H. (1997). A cognitive basis for the facilitation of spatial-temporal cognition through music instruction. In V. Brummett (Ed.), Ithaca Conference '96: Music as intelligence: A sourcebook (pp. 31-44). Ithaca, NY: Ithaca College.

Rauscher, F. H. (June 1999a). Music exposure and the development of spatial intelligence in children. Paper presented at the Cognitive Processes of Children Engaged in Musical Activity Conference, Urbana-Champaign, IL.

Rauscher, F. H. (1999b). Prelude or requiem for the 'Mozart effect'? Nature, 400, 827-828.

Rauscher, F. H., Bowers, M. K., \& Kohlbeck, K. (1999). Unpublished raw data.

Rauscher, F. H., \& Hayes, L. J. (1999). The effects of music exposure on spatial-temporal task performance: Exploring task validity in the "Mozart effect." Unpublished manuscript, University of Wisconsin, Oshkosh. 
Rauscher, F. H., \& Ribar, R. J. (1999). The Mozart effect: Discounting arousal. Unpublished manuscript, University of Wisconsin, Oshkosh.

Rauscher, F. H., Robinson, K. D., \& Jens, J. J. (1998). Improved maze learning through early music exposure in rats. Neurological Research, 20, 427-432.

Rauscher, F. H., \& Shaw, G. L. (1998). Key components of the Mozart effect. Perceptual and Motor Skills, 86, 835-841.

Rauscher, F. H., Shaw, G. L., \& Ky, K. N. (1993). Music and spatial task performance. Nature, 365, 611.

Rauscher, F. H., Shaw, G. L., \& Ky, K. N. (1995). Listening to Mozart enhances spatialtemporal reasoning: towards a neurophysiological basis. Neuroscience Letters, 185, 4447.

Richmond, G., \& Sachs, B. (1984). Further evidence for masculinization of female rats by males located caudally in utero. Hormones and Behavior, 18, 484-490.

Rideout, B. E., \& Laubach, C. M. (1996). EEG correlates of enhanced spatial performance following exposure to music. Perceptual and Motor Skills, 82, 427-432.

Reblitz, A. A. (1976). Piano servicing, tuning, \& rebuilding: For the professional, the student, the hobbyist. Vestal, NY: Vestal Press.

Shaw, G. L. (2000). Keeping Mozart in mind. San Diego, CA: Academic Press.

Shaw, G. L. (2001). The Mozart effect [Letter to the editor]. Epilepsy \& Behavior, 2, 611613.

Sohmer, H., \& Freeman, S. (1995). Functional development of auditory sensitivity in the fetus and neonate. Journal of Basic and Clinical Physiology and Pharmacology, 6, 95108.

Steele, K. M. (2000). Arousal and mood factors in the "Mozart effect." Perceptual and Motor Skills, 91, 188-190.

Steele, K. M., Ball, T. N., \& Runk, R. (1997). Listening to Mozart does not enhance backwards digit span performance. Perceptual and Motor Skills, 84, 1179-1184.

Steele, K. M., Bass, K. E., \& Crook, M. D. (1999). The mystery of the Mozart effect: Failure to replicate. Psychological Science, 10, 366-369.

Steele, K. M., Dalla Bella, S., Peretz, I., Dunlop, T., Dawe, L. A., Humphrey, G. K., et al. (1999). Prelude or requiem for the 'Mozart effect'? Nature, 400, 827.

Stephenson, V. P. (2002). The effect of classical background music on spatial reasoning skills as measured by completion of a spatial task: A study of selected college undergraduates. Dissertation Abstracts International, 63 (2-A), 464.

Stevens, S. S., \& Newman, E. B. (1934). The localization of pure tones. Proceedings of the National Academy of Sciences of the U.S.A., 20, 593-596.

Stevens, S. S., \& Newman, E. B. (1936). The localization of actual sources of sound. American Journal of Psychology, 48, 297-306.

Stough, C., Kerkin, B., Bates, T., \& Mangan, G. (1994). Music and spatial IQ. Personality and Individual Differences, 17, 695.

Thompson, W. F., Schellenberg, E. G., \& Husain, G. (2001). Arousal, mood, and the Mozart effect. Psychological Science, 12, 248-251.

Uziel, A., Romand, E., \& Marot, M. (1981). Development of cochlear potentials in rats. Audiology, 20, 89-100.

Weeks, S. P. (1996). The effect of music on abstract/visual reasoning performance in high school music and non-music students. (Doctoral dissertation, East Texas State University, 1995). UMI Dissertation Services No. 9600110.

Weiss, J. M. (1971). Effects of coping behavior with and without a feedback signal on stress pathology in rats. Journal of Comparative and Physiological Psychology, 77, 22-30. 